Article

\title{
Highly Efficient Cationic Palladium Catalyzed Acetylation of Alcohols and Carbohydrate-Derived Polyols
}

\author{
Enoch A. Mensah *, Francisco R. Reyes and Eric S. Standiford \\ Department of Physical Sciences, Indiana University Southeast, New Albany, IN 47150, USA; \\ frreyes@imail.iu.edu (F.R.R.); eric.standiford@gmail.com (E.S.S.) \\ * Correspondence: mensahe@ius.edu; Tel.: +1-812-941-2305; Fax: +1-812-941-2637 \\ Academic Editor: Kei Manabe \\ Received: 22 December 2015; Accepted: 3 February 2016; Published: 10 February 2016
}

\begin{abstract}
The development of a new facile method for the acetylation of alcohols and carbohydrate-derived polyols is described. This method relies on the nature of the cationic palladium catalyst, $\mathrm{Pd}(\mathrm{PhCN})_{2}(\mathrm{OTf})_{2}$ which is generated in situ from $\mathrm{Pd}(\mathrm{PhCN})_{2} \mathrm{Cl}_{2}$ and $\mathrm{AgOTf}$ to catalyze the acetylation reaction. This new acetylation protocol is very rapid and proceeds under mild conditions with only $1 \mathrm{~mol} \%$ of catalyst loading at room temperature. This new method has been applied to a variety of different alcohols with different levels of steric hindrance, as well as carbohydrate-derived polyols to provide the corresponding fully acetylated products in excellent yields.
\end{abstract}

Keywords: acetylation; acetic anhydride; cationic palladium (II) species; carbohydrate-derived polyols

\section{Introduction}

Manipulation of functional groups through their protection and deprotection is of prime importance in organic synthesis, resulting in the eventual synthesis of bioactive and medicinally important natural products. Of particular importance in this endeavor is the protection of hydroxy functional groups in reaction intermediates during multistep organic synthesis [1,2]. Of the various methods used to mask hydroxy groups, acetylation of hydroxy groups to the corresponding acetate esters is the most common, due to the ease of introduction of the acetyl group as well as its removal $[3,4]$. The traditional and the most widely used method of acetylating alcohols involve the use of acetic anhydride or acid chlorides in the presence of amine bases such as pyridine and trimethylamine [5]. While this traditional method of acetylating alcohols proceeds well, they usually require long reaction times, and the removal of pyridine is also tedious.

To circumvent these problems, several methods for the acetylation of alcohols have been reported in recent years. Some notable examples include the use of tributylphosphine [6,7], bromine [8], p-Toluenesulfonic acid [9], alumina [10], scandium triflate [11], indium triflate [12,13], bismuth triflate [14], trimethylsilyl triflate [15], copper triflate [16], cerium triflate [17], ruthenium chloride [18], sulfamic acid [19], montmorillonite K-10 [20], molecular sieves [21], iron (III)chloride [22], magnesium bromide [23], tantalum chloride [24], vanadyl acetate [25], N-bromosuccinamide (NBS) [26], 3-nitrobenzeneboronic acid [27], lithium perchlorate $\left(\mathrm{LiClO}_{4}\right)$ [28], silica gel supported sodium hydrogen sulfate [29], sodium acetate trihydrate [1], dried sodium bicarbonate [30] and Iodine [31,32]. While these methods provides viable alternative for acetylating alcohols, some of these methods utilizes catalysts that are expensive, moisture sensitive, require long reaction times and tedious work-up protocols and sometimes result in low yields. 
This therefore calls for the development of a new and simple acetylation protocol to complement the existing current methods for acetylating alcohols and polyols.

As a result of the earlier reports by the Nguyen research group in employing the use of cationic palladium (II) species to activate glycosyl trichloroacetimidates resulting in the stereoselective formation of glycosides [33,34], we hypothesized that these cationic palladium (II) species could equally be effective in activating acetic anhydride towards the acetylation of alcohols. This prompted us to investigate the effectiveness of these cationic palladium (II) species as catalyst in activating acetic anhydride towards the acetylation of alcohols. These cationic palladium catalysts are either commercially available or easy to prepare, easy to handle and stable. To the best of our knowledge, the use these catalysts in activating acetic anhydride towards the acetylation of alcohols has not been studied. We report herein a novel method that utilizes cationic palladium (II) species as catalyst in the acetylation of alcohols and carbohydrate-derived polyols.

\section{Results and Discussion}

To investigate the efficiency of the cationic palladium (II) species in activating acetic anhydride, a preliminary study of this new acetylation protocol was initiated using benzyl alcohol $\mathbf{1}$ as a model substrate and acetic anhydride 2 as the acetylation reagent (Table 1).

Table 1. Acetylation of benzyl alcohol catalyzed by cationic palladium (II) species.

\begin{tabular}{|c|c|c|c|c|c|}
\hline & + & $\begin{array}{c}\mathrm{Ac}_{2} \mathrm{O} \\
\text { (2 equiv.) } \\
2\end{array}$ & $\frac{\text { atalyst }}{\mathrm{CH}_{2} \mathrm{Cl}_{2}}$ & 3 & \\
\hline Entry & Catalyst & Loading (mol \%) & Temperature & Time (min) & Yield (\%) ${ }^{b}$ \\
\hline 1 & $\mathrm{Pd}\left(\mathrm{CH}_{3} \mathrm{CN}\right)_{4}\left(\mathrm{BF}_{4}\right)_{2}$ & 10 & $25^{\circ} \mathrm{C}$ & 30 & 75 \\
\hline 2 & $\mathrm{Pd}\left(\mathrm{CH}_{3} \mathrm{CN}\right)_{4}\left(\mathrm{BF}_{4}\right)_{2}$ & 5 & $25^{\circ} \mathrm{C}$ & 30 & 72 \\
\hline 3 & $\mathrm{Pd}(\mathrm{PhCN})_{2}(\mathrm{OTf})_{2}$ & 10 & $25^{\circ} \mathrm{C}$ & 5 & 95 \\
\hline 4 & $\mathrm{Pd}(\mathrm{PhCN})_{2}(\mathrm{OTf})_{2}$ & 7 & $25^{\circ} \mathrm{C}$ & 5 & 93 \\
\hline 5 & $\mathrm{Pd}(\mathrm{PhCN})_{2}(\mathrm{OTf})_{2}$ & 5 & $25^{\circ} \mathrm{C}$ & 5 & 96 \\
\hline 6 & $\mathrm{Pd}(\mathrm{PhCN})_{2}(\mathrm{OTf})_{2}$ & 2 & $25^{\circ} \mathrm{C}$ & 5 & 95 \\
\hline 7 & $\mathrm{Pd}(\mathrm{PhCN})_{2}(\mathrm{OTf})_{2}$ & 1 & $25^{\circ} \mathrm{C}$ & 5 & 95 \\
\hline
\end{tabular}

${ }^{a} \mathrm{Pd}(\mathrm{PhCN})_{2}(\mathrm{OTf})_{2}$ was generated in situ from $\mathrm{Pd}(\mathrm{PhCN})_{2} \mathrm{Cl}_{2}$ (1 equiv.) and $\mathrm{AgOTf}$ (2 equiv.) in $\mathrm{CH}_{2} \mathrm{Cl}_{2}(1.25 \mathrm{M})$.

${ }^{b}$ Isolated yield.

Upon treating the reacting partners 1 and 2 with $10 \mathrm{~mol} \%$ of a commercially available cationic palladium (II) catalyst, tetrakis(acetonitrile)palladium (II) bis tetrafluoroborate $\left(\mathrm{Pd}\left(\mathrm{CH}_{3} \mathrm{CN}\right)_{4}\left(\mathrm{BF}_{4}\right)_{2}\right)$, the acetylation reaction proceeded to completion within 30 minutes, as evident by TLC (Thin layer chromatography), affording the desired benzyl acetate 3 in good yield (Table 1, entry 1). This preliminary result was encouraging because it indicates that cationic palladium (II) catalyst could be employed in activating acetic anhydride towards the acetylation of alcohols. Upon reducing the catalyst loading to $5 \mathrm{~mol} \%$, there was no erosion of the isolated yield, and the reaction rate also remained unchanged (Table 1, entry 2). In our quest to further increase the catalytic activity of the cationic palladium (II) catalyst, we investigated the effect of the nature of the counter-ions used. Earlier reports in utilizing the nature of counter-ions to influence catalytic activity [35,36], prompted us to design a new cationic palladium (II) species $\mathrm{Pd}(\mathrm{PhCN})_{2}(\mathrm{OTf})_{2}$ as catalyst for the acetylation reaction. $\mathrm{Pd}(\mathrm{PhCN})_{2}(\mathrm{OTf})_{2}$ was generated in situ from commercially available $\mathrm{Pd}(\mathrm{PhCN})_{2} \mathrm{Cl}_{2}$ and AgOTf [33]. Upon treating the reacting partners 1 and 2 with $10 \mathrm{~mol} \%$ of the catalyst $\mathrm{Pd}(\mathrm{PhCN})_{2}(\mathrm{OTf})_{2}$, to our amazement, the acetylation reaction was very rapid, proceeding to completion within few minutes, and affording the benzyl acetate 3 in excellent yields (Table 1, entry 3). With these encouraging results, the acetylation reaction was repeated, each time using a progressively reduced catalyst loading up until a $1 \mathrm{~mol} \%$ catalyst loading. In all cases, the reaction was still rapid affording the benzyl acetate 3 
in excellent yields and with virtually no erosion of the isolated yields (Table 1, entry 4-7). This initial catalyst loading of $1 \mathrm{~mol} \%$ which resulted in the complete conversion of the benzyl alcohol 1 to the corresponding benzyl acetate 3 (Table 1, entry 7) generated a turnover number (TON) of 100 and a turnover frequency (TOF) of $1200 \mathrm{~h}^{-1}$.

With the optimum acetylation condition of $1 \mathrm{~mol} \%$ catalyst loading in hand, the efficacy of this catalyst was evaluated by comparing this protocol to other reported methods of acetylation of alcohols using benzyl alcohol as the model substrate (Table 2).

Table 2. Comparison of some acetylation methods with benzyl alcohol as substrate.

\begin{tabular}{cccccc} 
& & & \multicolumn{3}{c}{ Catalyst } \\
\cline { 3 - 6 } & Catalyst & Catalyst Loading (mol \%) & Time (min) & Yield (\%) & References \\
\hline 1 & $\mathrm{RuCl}_{3}$ & 5 & 10 & 95 & {$[18]$} \\
2 & $\mathrm{Cu}(\mathrm{OTf})_{2}$ & 2 & 30 & 97 & {$[16]$} \\
3 & $\mathrm{Bi}(\mathrm{TFA})_{3}$ & 5 & 60 & 96 & {$[37]$} \\
4 & $\mathrm{Cp}_{2} \mathrm{ZrCl}_{2}$ & 1 & 600 & 93 & {$[38]$} \\
$\mathbf{5}$ & $\mathbf{P d}(\mathbf{P h C N})_{\mathbf{2}}(\mathbf{O T f})_{2}$ & $\mathbf{1}$ & $\mathbf{5}$ & $\mathbf{9 5}$ & This work \\
\hline
\end{tabular}

While all these reported methods were able to efficiently catalyze the acetylation of benzyl alcohol to the benzyl acetate in excellent yields, the use of $\mathrm{Pd}(\mathrm{PhCN})_{2}(\mathrm{OTf})_{2}$ resulted in a complete conversion in relatively shorter time (Table 2, entry 5).

The efficacy of this catalyst, as well as its scope and limitations was evaluated by subjecting a wide variety of sterically and electronically diverse alcohols to this new acetylation condition (Table 3).

Table 3. Acetylation of alcohols with acetic anhydride catalyzed by $\mathrm{Pd}(\mathrm{PhCN})_{2}(\mathrm{OTf})_{2}$.

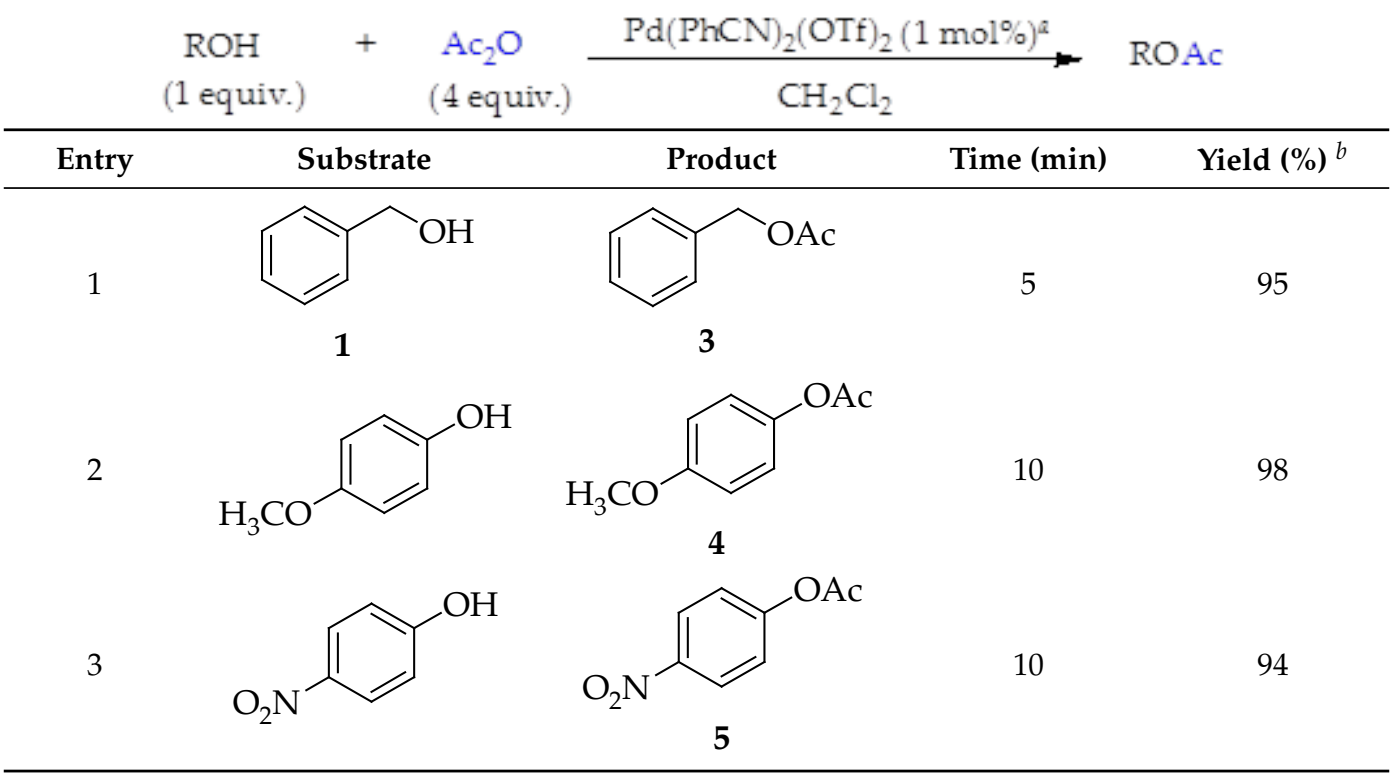


Table 3. Cont.

(min) Yield (\%) $^{b}$


Table 3. Cont.

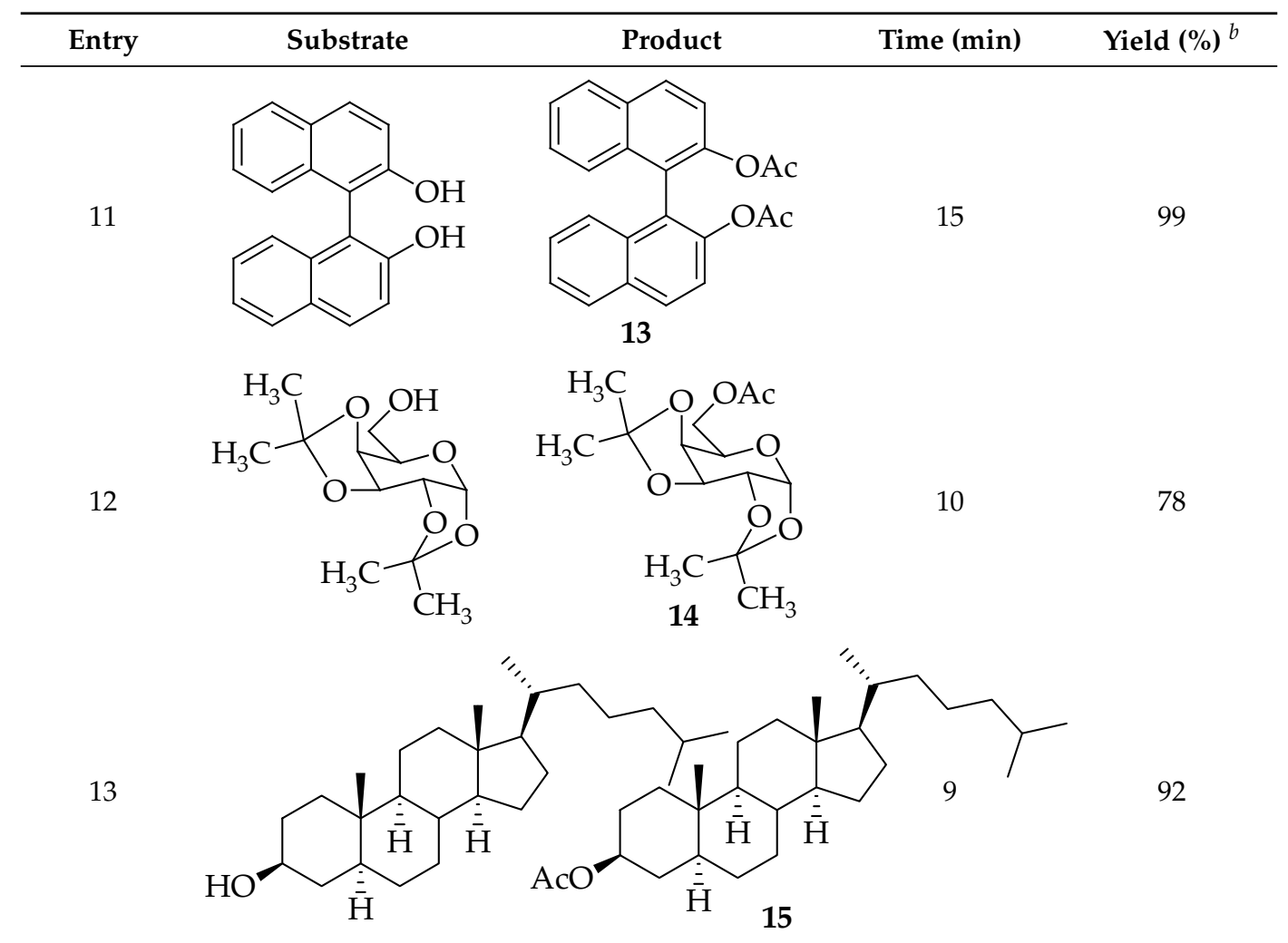

${ }^{a} \mathrm{Pd}(\mathrm{PhCN})_{2}(\mathrm{OTf})_{2}$ was generated in situ from $\mathrm{Pd}(\mathrm{PhCN})_{2} \mathrm{Cl}_{2}$ (1 equiv.) and $\mathrm{AgOTf}$ (2 equiv.) in $\mathrm{CH}_{2} \mathrm{Cl}_{2}(1.25 \mathrm{M})$.

${ }^{b}$ Isolated yield.

In all cases, the acetylation reaction proceeded smoothly and rapidly affording the corresponding acetates in excellent yields. Particularly interesting is the acetylation of highly deactivated alcohols such as 4-nitrophenol and 2,4-dinitrophenol, which were completely acetylated at short reaction times affording the corresponding acetate 5 and 6 in excellent yields (Table 3, entry 3-4).

The efficacy of this cationic palladium (II) catalyst was again evaluated using highly hindered alcohols such as adamantanol and diphenylmethanol. In both cases, the acetylation reaction proceeded well affording the acetylated products 7 and 8 in excellent yields (Table 3, entry 5 -6).

Since acetylation of monosaccharides is usually the first step towards the synthesis of complex carbohydrates [12], the efficacy of this cationic palladium (II) catalyst $\mathrm{Pd}(\mathrm{PhCN})_{2}(\mathrm{OTf})_{2}$ in the acetylation of carbohydrate-derived polyol was also investigated (Table 4).

In this acetylation, two equivalent of acetic anhydride was used for every hydroxy group. In all cases, the acetylation reaction afforded the acetylated sugars 16-22 in excellent yields (Table 4, entry 1-7).

To determine the scope and limits of this new acetylation reaction, the tolerance of the $\mathrm{Pd}(\mathrm{PhCN})_{2}(\mathrm{OTf})_{2}$ catalyzed acetylation with several acid sensitive hydroxy protecting groups were also investigated. While the acetonide group, TBDPS and PMP ( $p$-methoxyphenyl) protecting groups were stable under the present acetylation protocol, affording the corresponding acetylated products in excellent yields (Table 3, entry 12; Table 4 entry 6-7), TMS and TBS groups were unstable and subsequently hydrolyzed, and the resulting hydroxy group acetylated. It was also noted that there was a gradual loss of the acetonide group when the acetylation reaction was carried out for an extended period. 
Table 4. $(\mathrm{PhCN})_{2} \mathrm{Pd}(\mathrm{OTf})_{2}$ catalyzed acetylation of carbohydrate-derived polyols.

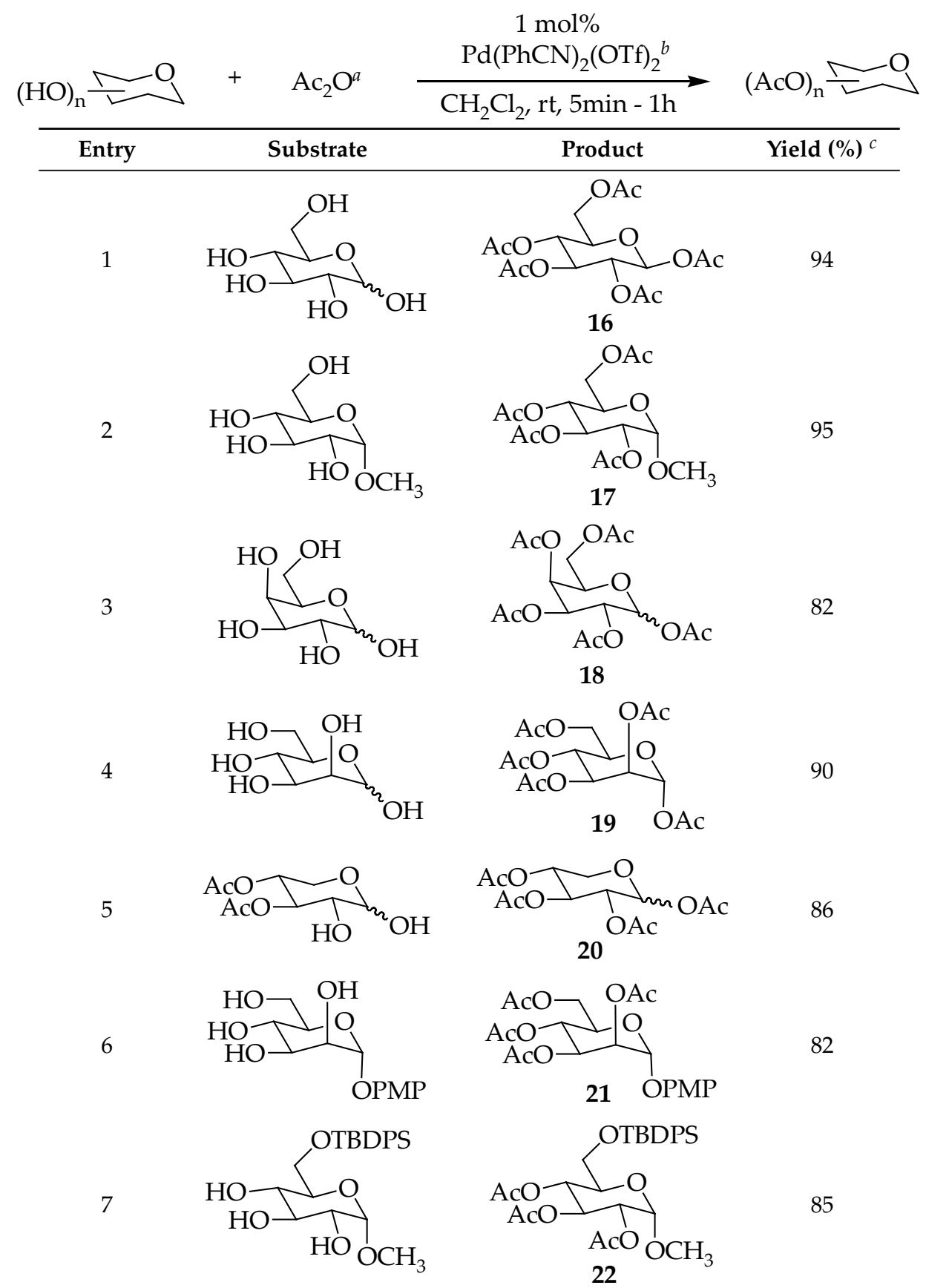

a 2 equiv. of acetic anhydride were used per hydroxy group. ${ }^{b} \mathrm{Pd}(\mathrm{PhCN})_{2}(\mathrm{OTf})_{2}$ was generated in situ from $\mathrm{Pd}(\mathrm{PhCN})_{2} \mathrm{Cl}_{2}$ (1 equiv.) and $\mathrm{AgOTf}\left(2\right.$ equiv.) in $\mathrm{CH}_{2} \mathrm{Cl}_{2}(1.25 \mathrm{M}) .{ }^{c}$ Isolated yield.

With these exciting results, the substrate scope of $\mathrm{Pd}(\mathrm{PhCN})_{2}(\mathrm{OTf})_{2}$ was further evaluated by extending it to the acetylation of disaccharide-derived polyols (Scheme 1). 


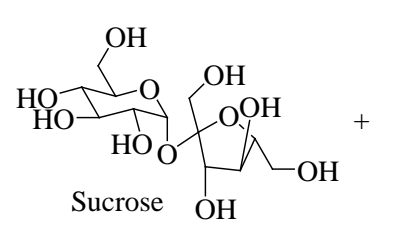

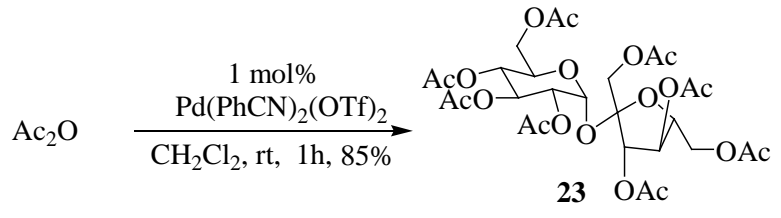

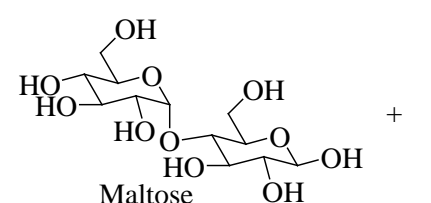

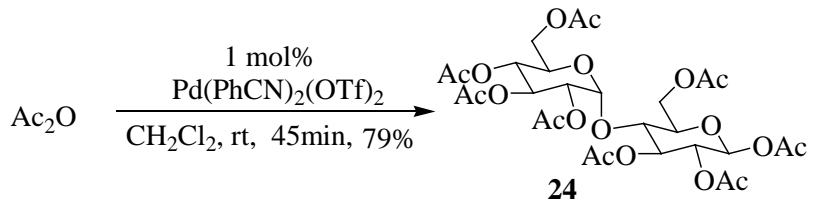

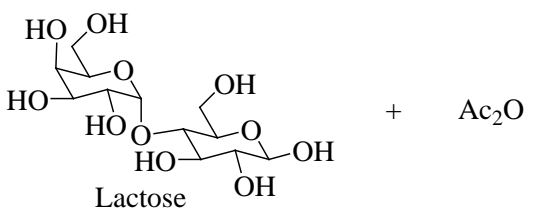

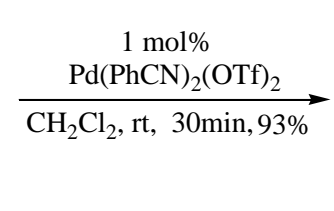

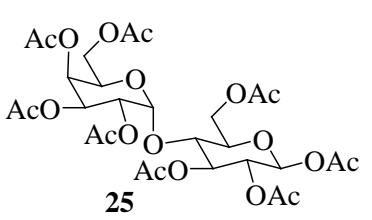

Scheme 1. $\mathrm{Pd}(\mathrm{PhCN})_{2}(\mathrm{OTf})_{2}$ catalyzed acetylation of disaccharide-derived polyols.

Using sucrose, maltose and lactose as starting materials, the corresponding acetylated disaccharides 23, 24 and 25 were isolated in good to excellent yields using only $1 \mathrm{~mol} \%$ catalyst loading.

With these excellent conversions and catalyst turnover, we proceeded to explore the origin of the observed catalytic activity by conducting a number of control experiments using benzyl alcohol as the model substrate (Table 5).

Table 5. A control experiment with benzyl alcohol as substrate.

\begin{tabular}{|c|c|c|c|c|c|}
\hline Entry & Catalyst & Loading & Additive & Time & Yield $(\%)^{c}$ \\
\hline 1 & No catalyst & - & - & $5 \mathrm{~h}$ & $<1$ \\
\hline 2 & $\mathrm{Pd}(\mathrm{PhCN})_{2} \mathrm{Cl}_{2}$ & $1 \mathrm{~mol} \%$ & - & $5 \mathrm{~h}$ & $<1$ \\
\hline 3 & $\mathrm{AgOTf}$ & $2 \mathrm{~mol} \%$ & - & $5 \mathrm{~h}$ & 5 \\
\hline 4 & $\mathrm{Pd}(\mathrm{PhCN})_{2}(\mathrm{OTf})_{2}^{a}$ & $1 \mathrm{~mol} \%$ & - & $5 \mathrm{~min}$ & 95 \\
\hline 5 & $\mathrm{Pd}(\mathrm{PhCN})_{2}(\mathrm{OTf})_{2}$ & $1 \mathrm{~mol} \%$ & $\mathrm{DTBP}^{b}$ & $2 \mathrm{~h}$ & 90 \\
\hline 6 & $\mathrm{TfOH}$ & $2 \mathrm{~mol} \%$ & - & $8 \mathrm{~min}$ & 86 \\
\hline 7 & $\mathrm{Pd}(\mathrm{PhCN})_{2}(\mathrm{OTf})_{2}{ }^{a}$ & $1 \mathrm{~mol} \%$ & $\operatorname{Hg}(0)$ & $5 \mathrm{~min}$ & 93 \\
\hline 8 & $\mathrm{Pd}\left(\mathrm{CH}_{3} \mathrm{CN}\right)_{4}(\mathrm{OTf})_{2}$ & $1 \mathrm{~mol} \%$ & - & $5 \mathrm{~min}$ & 92 \\
\hline
\end{tabular}

There was virtually no product isolation when the acetylation reaction was conducted in the absence of a catalyst and stirred for 5 hours (Table 5 , entry 1 ).

To determine whether the observed acetylation reactions were due to the catalyst precursors $\mathrm{Pd}(\mathrm{PhCN})_{2} \mathrm{Cl}_{2}$ and AgOTf, two separate control experiments were conducted with neutral palladium (II) species $\mathrm{Pd}(\mathrm{PhCN})_{2} \mathrm{Cl}_{2}$ and $\mathrm{AgOTf}$ as catalyst at $1 \mathrm{~mol} \%$ and $2 \mathrm{~mol} \%$ catalyst loading respectively, and at room temperature. In both cases, the acetylated products obtained were negligible (Table 5, entry 2-3). These results may suggest that the observed catalytic activity was neither due to the neutral palladium (II) species nor those of AgOTf under the present reaction conditions, but rather cationic palladium (II) catalysts.

To determine if triflic acid, which may potentially be generated from $\mathrm{Pd}(\mathrm{PhCN})_{2}(\mathrm{OTf})_{2}$, is the source of the observed catalysis, the acetylation reaction was performed in the presence of 
2,6-di-tert-butylpyridine (DTBP) (5 mol\%). Surprisingly, the reaction was quite sluggish, affording the desired benzyl acetate in excellent yields (Table 5, entry 5). This result may suggest that while cationic palladium (II) catalyst $\mathrm{Pd}(\mathrm{PhCN})_{2}(\mathrm{OTf})_{2}$ is primarily responsible for the observed acetylation reactions, we cannot rule out the involvement of a trace side reaction due to Bronsted acid catalysis.

To probe further the origin of the observed catalysis, another control experiment was conducted with triflic acid ( $2 \mathrm{~mol} \%)$ as catalyst. Interestingly, the acetylation reaction yielded benzyl acetate in good yields (Table 5, entry 6). This results may signal the presence of a dual catalytic process in the acetylation reaction. A similar dual pathway was reported by the Cloninger group with $\operatorname{In}(\mathrm{OTf})_{2}[12]$.

To probe the nature of palladium responsible for the observed catalysis, the acetylation of the benzyl alcohol was carried out in the presence of large excess $\mathrm{Hg}(0)(\mathrm{Hg}$ drop test). In this control experiment, the acetylation reaction was still rapid with virtually no erosion of the isolated yield of the benzyl acetate (Table 5, entry 7). The result was very significant, and may suggest the absence of $\operatorname{Pd}(0)$ or palladium nanoparticles (Pd-NPs) as the source of catalysis.

To probe further the source of the observed catalysis, another control experiment was conducted using a commercially available cationic $\mathrm{Pd}(\mathrm{II})$ catalyst $\mathrm{Pd}\left(\mathrm{CH}_{3} \mathrm{CN}\right)_{4}(\mathrm{OTf})_{2}$. To our excitement, the acetylation reaction proceeded smoothly affording the benzyl acetate in excellent yields (Table 5, entry 8). This exciting results may suggest the significant role of cationic palladium (II) species in effecting the acetylation of alcohols.

\section{Experimental Section}

\subsection{Materials and Methods}

All acetylation reactions were performed in an oven-dried and argon flushed round bottom flask. Analytical thin-layer chromatography (TLC) was routinely used to monitor the reaction progress, and was performed using a pre-coated glass plates with 230-400 mesh silica gel. The dichloromethane used to prepare the catalyst was distilled from calcium hydride under an argon atmosphere. All other chemicals were obtained from commercial vendors and used without further purification.

Identification of the products was carried out using IR, ${ }^{1} \mathrm{H}$ NMR and ${ }^{13} \mathrm{C}$ NMR. The ${ }^{1} \mathrm{H}$ NMR spectra were recorded on a Varian $500 \mathrm{MHz}, 600 \mathrm{MHz}$ and $700 \mathrm{MHz}$ spectrometers. The ${ }^{13} \mathrm{C}$ NMR spectra were recorded on a Varian $125 \mathrm{MHz}, 150 \mathrm{MHz}$ and $175 \mathrm{MHz}$ spectrometers using $\mathrm{CDCl}_{3}$ as reference solvent. The IR and NMR data of the products formed were consistent with those previously reported.

\subsection{Typical Experimental Procedure for Acetylation of Alcohols}

An oven dried and argon flushed $10 \mathrm{~mL}$ round-bottom flask was charged with benzyl alcohol ( $52 \mu \mathrm{L}, 0.50 \mathrm{mmol}, 1.0$ equiv.) and acetic anhydride ( $0.19 \mathrm{~mL}, 2.0 \mathrm{mmol}, 4.0$ equiv.). To this mixture was added a preformed solution of $\mathrm{Pd}(\mathrm{PhCN})_{2}(\mathrm{OTf})_{2}(0.2 \mathrm{~mL}, 0.005 \mathrm{mmol}, 1 \mathrm{~mol} \%)$, which was generated in situ from $\mathrm{Pd}(\mathrm{PhCN})_{2} \mathrm{Cl}_{2}(1.92 \mathrm{mg}, 0.005 \mathrm{mmol}, 1 \mathrm{~mol} \%)$ and AgOTf $(2.57 \mathrm{mg}, 0.01 \mathrm{mmol}, 2 \mathrm{~mol} \%)$ in anhydrous dichloromethane $(0.2 \mathrm{~mL})$. The reaction mixture was stirred at room temperature. When the reaction was completed as evidenced by TLC, the excess acetic anhydride was quenched with saturated aqueous $\mathrm{NaHCO}_{3}(2 \mathrm{~mL})$ and stirred for $45 \mathrm{~min}$. The resulting reaction mixture was directly introduced onto a short $\mathrm{SiO}_{2}$ column and purified by flash column chromatography $(4 / 1$, hexanes/ethyl acetate) to afford the benzyl acetate as pale yellow oil.

\section{Conclusions}

In summary, a novel method for acetylation of alcohols has been developed. This method is highly efficient and proceeds under mild conditions requiring only $1 \mathrm{~mol} \%$ of catalyst loading at room temperature. The method is applicable to a wide variety of alcohols with different levels of steric hindrance, and has been extended to the acetylation of carbohydrate-derived polyols. 
Acknowledgments: We gratefully acknowledge financial support from Indiana University Southeast. This research is also supported by Indiana University Southeast Research Support Program as well as the Indiana University Southeast Large Grant Program.

Author Contributions: Enoch Mensah conceived and designed the experiments. Francisco Reyes, Eric Standiford and Enoch Mensah performed the experiments.

Conflicts of Interest: The authors declare no conflict of interest.

\section{References and Notes}

1. Mojtahedi, M.M.; Samadian, S. Efficient and Rapid Solvent-Free Acetylation of Alcohols, Phenols, and Thiols Using Catalytic Amounts of Sodium Acetate Trihydrate. J. Chem. 2013, 2013, 1-7. [CrossRef]

2. Petursson, S. Diarylmethyl ethers for the protection of polyols. J. Chem. 2013, 2013. Article ID 183049:1-183049:10. [CrossRef]

3. Shirini, F.; Zolfigol, M.A.; Safari, A. A mild and efficient method for the acetylation of alcohols. Indian J. Chem. 2005, 44B, 201-203. [CrossRef]

4. Heravi, M.M.; Behbahani, F.K.; Bamoharram, F.F. Acetylation of alcohols, phenols and salicylic acid by heteropoly acids in acetic anhydride: A green and eco-friendly protocol for synthesis of acetyl salicylic acid (Aspirin). ARKIVOC 2007, xvi, 123-131.

5. Zhdanov, R.I.; Zhenodarova, S.M. A Mild and Efficient Method for the Acetylation of Alcohols. Synthesis $1975,44 B, 222$.

6. Vedejs, E.; Bennett, N.S.; Conn, L.M.; Diver, S.T.; Gingras, M.; Lin, S.; Oliver, P.A.; Peterson, M.J. Tributylphosphine-catalyzed acylations of alcohols: Scope and related reactions. J. Org. Chem. 1993, 58, 7286-7288. [CrossRef]

7. Vedejs, E.; Diver, S.T. Tributylphosphine: A remarkable Acylation Catalyst. J. Am. Chem. Soc. 1993, 115, 3358-3359. [CrossRef]

8. Khan, A.T.; Choudhury, L.H.; Ghosh, S. Acetonyltriphenylphosphonium Bromide (ATPB): A Versatile Reagent for the Acylation of Alcohols, Phenols, Thiols and Amines and for 1,1-Diacylation of Aldehydes under Solvent-Free Conditions. Eur. J. Org. Chem. 2005, 2782-2787. [CrossRef]

9. For p-Toluenesulfonic acid refer to Cope, A.C.; Herrich, E.C. Org. Synth. Coll. 1963, 4, 304.

10. Breton, G.W.; Kurtz, M.J.; Kurtz, S.L. Acetylation of unsymmetrical diols in the presence of $\mathrm{Al}_{2} \mathrm{O}_{3}$. Tetrahedron Lett. 1997, 38, 3825-3828. [CrossRef]

11. Ishihara, K.; Kubota, M.; Kurihara, H.; Yamamoto, H. Scandium Trifluoromethanesulfonate as an extremely active lewis acid catalyst in acylation of alcohols with acid anhydrides and mixed anhydrides. J. Org. Chem. 1996, 61, 4560-4567. [CrossRef] [PubMed]

12. Bizier, N.P.; Atkins, S.R.; Helland, L.C.; Colvin, S.F.; Twitchell, J.R.; Cloninger, M.J. Indium triflate catalyzed peracetylation of carbohydrates. Carbohydr. Res. 2008, 343, 1814-1818.

13. Chauhan, K.K.; Frost, C.G.; Love, I.; Waite, D. Indium triflate: An efficient catalyst for acylation reactions. Synlett 1999, 1743-1744. [CrossRef]

14. Orita, A.; Tanahashi, C.; Kakuda, A.; Otera, J. Highly Efficient and versatile acylation of alcohols with Bi(OTf $)_{3}$ as catalyst. Angew. Chem. Int. Ed. 2000, 39, 2877-2879.

15. Procopiou, P.A.; Baugh, S.P.D.; Flack, S.S.; Inglis, G.G.A. An extremely fast and efficient acylation reaction of alcohols with acid anhydrides in the presence of trimethylsilyl trifluoromethanesulfonate as catalyst. Chem. Commun. 1996, 23, 2625-2626. [CrossRef]

16. Saravanan, P.; Singh, V.K. An efficient method for acylation reactions. Tetrahedron Lett. 1999, 40, $2611-2614$. [CrossRef]

17. Dalpozzo, R.; De Nino, A.; Maiuolo, L.; Procopio, A.; Nardi, M.; Bartoli, M.; Romeo, R. Highly efficient and versatile acetylation of alcohols catalyzed by cerium(III) triflate. Tetrahedron Lett. 2003, 44, 5621-5624. [CrossRef]

18. De, S.K. Ruthenium(III) chloride catalyzed acylation of alcohols, phenols, thiols, and amines. Tetrahedron Lett. 2004, 45, 2919-2922. [CrossRef]

19. Jin, T.S.; Ma, Y.R.; Zhang, Z.H.; Li, T.S. Sulfamic acid catalysed acetylation of alcohols and phenols with acetic anhydride. Synth. Commun. 1998, 28, 3173-3177. [CrossRef] 
20. Bhaskar, P.M.; Loganathan, D. Per-O-acetylation of sugars catalysed by montmorillonite K-10. Tetrahedron Lett. 1998, 39, 2215-2218. [CrossRef]

21. Adinolfi, M.; Barone, G.; Iadonisi, A.; Schiattarella, M. An easy approach for the acetylation of saccharidic alcohols. Applicability for regioselective protections. Tetrahedron Lett. 2003, 44, 4661-4663. [CrossRef]

22. Dasgupta, F.; Singh, P.P.; Srivastava, H.C. Acetylation of carbohydrates using ferric chloride in acetic anhydride. Carbohydr. Res. 1980, 80, 346-349. [CrossRef]

23. Pansare, S.V.; Malusara, M.G.; Rai, A.N. Magnesium bromide catalysed acylation of alcohols. Synth. Commun. 2000, 30, 2587-2592. [CrossRef]

24. Chandrasekhar, S.; Ramachander, T.; Takhi, M. Acylation of alcohols with acetic anhydride catalyzed by $\mathrm{TaCl}_{5}$ : Some implications in kinetic resolution. Tetrahedron Lett. 1998, 39, 3263-3266. [CrossRef]

25. Choudary, B.M.; Kantam, M.L.; Neeraja, V.; Bandyopadhyay, T.; Reddy, P.N. Vanadyl(IV) acetate, a new reusable catalyst for acetylation of alcohols. J. Mol. Catal. A 1999, 140, 25-29. [CrossRef]

26. Karimi, B.; Seradj, H. N-Bromosuccinimide (NBS), a novel and highly effective catalyst for acetylation of alcohols under mild reaction conditions. Synlett 2001, 519-520. [CrossRef]

27. Tale, R.H.; Adude, R.N. A novel 3-nitrobenzeneboronic acid as an extremely mild and environmentally benign catalyst for the acetylation of alcohols under solvent-free conditions. Tetrahedron Lett. 2006, 47, 7263-7265. [CrossRef]

28. Lu, K.C.; Hsieh, S.Y.; Patkar, L.N.; Chen, C.T.; Lin, C.C. Simple and efficient per-O-acetylation of carbohydrates by lithium perchlorate catalyst. Tetrahedron 2004, 60, 8967-8973. [CrossRef]

29. Breton, G.W. Selective monoacetylation of unsymmetrical diols catalyzed by silica gel-supported sodium hydrogen sulfate. J. Org. Chem. 1997, 62, 8952-8954. [CrossRef]

30. Lugemwa, F.N.; Shaikh, K.; Hochstedt, E. Facile and efficient acetylation of primary alcohols and phenols with acetic anhydride aatalyzed by dried sodium bicarbonate. Catalysts 2013, 3, 954-965. [CrossRef]

31. Borah, R.; Deka, N.; Sarma, J.C. Iodine as an Acetyl Transfer Catalyst. J. Chem. Res. 1997, 110-111. [CrossRef]

32. Kartha, K.P.R.; Field, R.A. Iodine: A versatile reagent in carbohydrate chemistry IV. Per-O-acetylation, regioselective acylation and acetolysis. Tetrahedron 1997, 53, 11753-11766.

33. Mensah, E.A.; Azzarelli, J.M.; Nguyen, H.M. Palladium-controlled $\beta$-selective glycosylation in the absence of the C(2)-ester participatory group. J. Org. Chem. 2009, 74, 1650-1657. [CrossRef] [PubMed]

34. Jang, J.; Cooper-Vanosdell, C.; Mensah, E.A.; Nguyen, H.M. Cationic palladium(II)-catalyzed stereoselective glycosylation with glycosyl trichloroacetimidates. J. Org. Chem. 2008, 73, 794-800.

35. Reed, C.A. Carboranes: A new class of anions for strong electrophiles, oxidants and superacids. Acc. Chem. Res. 1998, 31, 133-139. [CrossRef]

36. Mecking, S. Cationic nickel and palladium complexes with bidentate ligands for the C-C linkage of olefins. Coord. Chem. Rev. 2000, 203, 325-351. [CrossRef]

37. Mohammadpoor-Baltork, I.; Aliyan, H.; Khosropour, A.R. Bismuth(III) salts as convenient and efficient catalysts for the selective acetylation and benzoylation of alcohols and phenols. Tetrahedron 2001, 57, 5851-5854. [CrossRef]

38. Kantam, M.L.; Aziz, K.; Likhar, P.R. Bis(cyclopentadienyl) zirconium dichloride catalyzed acetylation of phenols, alcohols and amines. Catal. Commun. 2006, 7, 484-487. [CrossRef]

(C) 2016 by the authors; licensee MDPI, Basel, Switzerland. This article is an open access article distributed under the terms and conditions of the Creative Commons by Attribution (CC-BY) license (http://creativecommons.org/licenses/by/4.0/). 